\title{
Analisis Hasil Implementasi Business Intelligence Menentukan Daerah Rawan Banjir dan Kebakaran di Indonesia
}

\author{
Ricky Akbar $^{\# 1}$,Nurman Abedi ${ }^{\# 2}$, Rahmi Handayani" ${ }^{\#}$, Ugi Meiliya Eka Putri ${ }^{\#}$

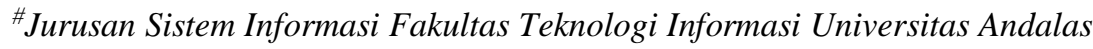 \\ Jln.Limau Manis, Pauh 25163, Padang, Sumatera Barat \\ 1rickyakbar1984@gmail.com \\ 2nurmanm91@gmail.com
}

\begin{abstract}
Abstrak - Bencana akan menimbulkan kerugian di berbagai aspek kehidupan masyarakat baik berupa kerugian materiil dan kerugian moril. Kerugian moril yang timbul seperti kondisi mental yang menurun atau terganggu karena seseorang akan kehilangan keluarga dan harta benda akibat bencana tersebut. Banjir dan kebakaran merupakan bencana yang marak terjadi di Indonesia. Banjir menempati posisi pertama sebagai bencana yang terjadi di setiap tahunnya. Badan Nasional Penanggulangan Bencana (BNPB) adalah salah satu badan yang ada di Indonesisa yang mempunyai tugas membantu Presiden Republik Indonesia untuk mengkoordinasikan perencanaan dan pelaksanaan kegiatan penanganan bencana dan kedaruratan secara terpadu, serta melaksanakan penanganan bencana dan kedaruratan mulai dari sebelum, pada saat, dan setelah terjadi bencana yang meliputi pencegahan, kesiapsiagaan, penanganan darurat, dan pemulihan. Badan ini tentu memiliki data yang sangat banyak mengenai bencana yang telah terjadi. Hal tersebut tentu memerlukan sebuah aplikasi untuk memetakan atau mengelompokkan data-data yang ada sehingga lebih sistematis. Sehingga dapat memberikan informasi berupa provinsi yang rawan bencana dan aman dari bencana khusunya banjir dan kebakaran. Penerapan Business Inteligence sangat cocok untuk kasus ini agar BNPB dapat mengelompokkan bencana khususnya banjir dan kebakaran di setiap provinsi yang ada di Indonesia untuk mempermudah masyarakat mendapat informasi bencana yang terjadi. Secara umum, Business Inteligence bertujuan untuk menyajikan berbagai informasi-informasi sesuai dengan kebutuhan setiap penggunanya. Pada penelitian ini menggunakan salah satu aplikasi Business Inteligence yakni JasperServer untuk dapat mengelompokkan bencana banjir dan kebakaran yang terjadi di setiap provinsi yang ada di Indonesia.
\end{abstract}

Kata kunci- Business Intelligence, Bencana, Banjir, Kebakaran, JasperServer.

\section{Pendahuluan}

Menurut UU Nomor 24 Tahun 2007, bencana adalah peristiwa atau rangkaian peristiwa yang mengancam dan mengganggu kehidupan dan penghidupan masyarakat yang disebabkan, baik oleh faktor alam dan/atau faktor non alam maupun faktor manusia sehingga mengakibatkan timbulnya korban jiwa manusia, kerusakan lingkungan, kerugian harta benda, dan dampak psikologis. Bencana terjadi karena adanya ancaman, dampak dan kerentanan. Bencana dapat mengancam semua wilayah di Indonesia baik di wilayah daratan maupun lautan.

Badan Nasional Penanggulangan Bencana (BNPB) adalah sebuah Lembaga Pemerintah Non Departemen yang memiliki tugas untuk membantu Presiden Republik Indonesia dalam mengkoordinasikan perencanaan dan pelaksanaan kegiatan penanganan bencana dan kedaruratan secara terpadu, serta melaksanakan penanganan bencana dan kedaruratan mulai dari sebelum, pada saat, dan setelah terjadi bencana yang meliputi pencegahan, kesiapsiagaan, penanganan darurat, dan pemulihan. Badan ini merupakan badan yang memiliki seluruh data bencana baik bencana alam maupun nonalam yang terjadi di Indonesia.

Banjir dan kebakaran adalah dua diantara jenis bencana yang terjadi Indonesia. Banjir merupakan peristiwa yang terjadi ketika aliran air yang berlebihan merendam daratan. Banjir juga merupakan bencana yang paling sering terjadi di Indonesia. Sedangkan kebakaran adalah sesuatu bencana yang disebabkan oleh api atau pembakaran tidak terkawal yang membahayakan nyawa manusia, bangunan atau ekologi. Kebaran merupakan bencana yang paling sering dihadapi. Kebakara itu sendiri bisa digolongkan sebagai bencana alam atau bencana yang disebabkan oleh manusia. Bahaya kebakaran dapat terjadi setiap saat, karena banyak peluang yang dapat memicu terjadinya kebakaran.

Banyaknya data bencana khusunya banjir dan kebakaran yang ada pada BNPB tentu harus dapat terorganisir dan sistematis sehingga mempermudah dalam pengambilan keputusan. Misalnya pengelompokkan bencana banjir dan kebakaran di setiap provinsi yang ada di Indonesia. Pengelompokkan ini tentu bertujuan agar masyarakat dan BNPB khusunya dapat mengetahui provinsi mana saja yang rawan bencana dan provinsi yang aman dari bencana. Penerapan Business Intelligence merupakan salah satu solusi terbaik untuk mengatasinya. Business Intelligence meliputi perolehan data dan informasi dari berbagai sumber yang bervariasi dan mengolahnya ke dalam pengambilan keputusan.

Pada penelitian kali ini, dibutuhkan sebuah aplikasi Business Intelligence untuk membantu BNPB untuk mengkoordinir data yang dimilikinya. JasperServer adalah 
salah satu aplikasi Business Intelligence yang digunakan pada penelitiaan ini untuk dapat mengelompokkan provinsi yang ada di Indonesia termasuk provinsi yang aman bencana atau rawan bencana berdasarkan data yang diperoleh dari BNPB khusunya banjir dan kebakaran.

\section{STUDI LITERATUR}

\section{A. Business Intelligence}

Business Intelligence membahas tentang suatu konsep dan metode bagaimana cara untuk meningkatkan kualitas pengambilan keputusan bisnis berdasarkan sistem yang berbasiskan data. Business Intelligence bisa disamakan dengan briefing books, report dan query tools, serta sistem informasi eksekutif. Business Intelligence merupakan sistem pendukung pengambilan keputusan yang berbasiskan data-data [1]

Konsep Business Intelligence menekankan pada penerapan 5 pendayagunaan informasi untuk keperluan spesifik bisnis, masing-masing adalah sebagai berikut:

1. Data Sourcing

Berkaitan dengan kemampuan sistem untuk mengakses berbagai data dan informasi dari sejumlah sumber dengan format yang berbeda.

2. Data Analysis

Berkaitan dengan kemampuan sistem dalam membantu proses penciptaan pengetahuan (knowledge) melalui aktivitas pengkajian informasi dan data yang dimiliki oleh perusahaan.

3. Situation Awareness

Berkaitan dengan kemampuan sistem untuk mencari dan menyediakan informasi dan data terkait dengan kebutuhan atau konteks bisnis pada saat tertentu, misalnya ketika perusahaan berhadapan dengan peristiwa darurat dan mendesak.

4. Risk Analysis

Berkaitan dengan kemampuan sistem untuk melakukan kalkulasi rasio yang akan dihadapi perusahaan terhadap berbagai kecenderungan atau kemungkinan yang dapat terjadi sehubungan dengan kondisi tertentu.

5. Decission Support

Berkaitan dengan kemampuan sistem untuk secara aktif membantu manajemen dalam memberikan pertimbangan keputusan-keputusan yang berkualitas berdasarkan sejumlah kalkulasi dan pengolahan terhadap data atau informasi internal maupun eksternal yang dimiliki [2].

Langkah - langkah proses Business Intelligence menurut Ronald ada beberapa bagian dalam solusi Business Intelligence yaitu :

1. Identifikasi masalah bisnis yang perlu diselesaikan dengan gudang data dan menentukan data yang diperlukan untuk menyelesaikan masalah tersebut.

2. Identifikasi lokasi dari data-data yang diperlukan dan mengambilnya dari sumber penyimpanannya.

3. Merubah data yang diperoleh dari beragam sumber tersebut ke dalam sebuah data yang konsisten.
4. Mengambil data yang telah dirubah tersebut ke dalam lokasi yang yang tersentralisasi.

5. Membuat sebuah gudang data dengan data yang ada dalam lokasi yang tersentralisasi tersebut (Data Warehouse) [3].

Beberapa manfaat yang diperoleh oleh suatu perusahaan atau organisasi saat mengimplementasikan Business Intelligence, yakni :

1. Meningkatkan nilai informasi dan data organisasi. Melalui pembangunan Business Intelligence, seluruh informasi dan data dapat diintegrasikan sedemikian rupa sehingga menghasilkan pengambilan keputusan yang lengkap.

2. Memudahkan pemantauan kinerja organisasi. Dalam mengukur kinerja suatu organisasi, seringkali dipergunakan ukuran yang disebut Key Performance Indicator (KPI). Business Intelligence dapat dengan mudah menunjukkan pencapaian KPI suatu organisasi dengan mudah, cepat, dan tepat. Dengan demikian, akan memudahkan pihak-pihak yang terlibat dalam pengambilan keputusan untuk langkah-langkah antisipasi yang diperlukan.

3. Meningkatkan nilai investasi teknologi informasi yang sudah ada. Business Intelligence tidak selalu harus mengubah atau menggantikan sistem informasi yang sudah digunakan sebelumnya. Sebaliknya, Business Intelligence hanya menambahkan layanan pada sistem-sistem tersebut sehingga data dan informasi yang sudah ada dapat menghasilkan informasi yang komprehensif dan memiliki kegunaan yang lebih baik.

4. Menciptakan pegawai yang memiliki akses informasi yang baik (well-informed workers). Dalam melaksanakan pekerjaannya sehari-hari, seluruh level dari suatu organisasi (mulai dari pegawai/bawahan sampai dengan pimpinan) selalu berkaitan dan atau membutuhkan akses data dan informasi. Business Intelligence mempermudah seluruh level pegawai dalam mengakses data dan informasi yang diperlukan sehingga membantu membuat suatu keputusan. Jika seperti ini tercapai, maka misi dan strategi organisasi yang sudah ditetapkan dapat lebih mudah terlaksana terpantau tingkat pencapaiannya.

5. Meningkatkan efisiensi biaya. Melalui Business Intelligence dapat meningkatkan efisiensi karena mempermudah seseorang dalam melakukan pekerjaan, hemat waktu, dan mudah pemanfaatannya. Waktu yang dibutuhkan untuk mencari data dan mendapatkan informasi yang dibutuhkan semakin singkat dan cara untuk mendapatkannya pun tidak memerlukan pengetahuan (training) yang rumit [4].

\section{B. Bencana}

Dalam Undang-Undang No 24 Tahun 2007 tentang Penanggulangan Bencana, dikenal pengertian dan beberapa istilah terkait dengan bencana. 
1. Bencana adalah peristiwa atau rangkaian peristiwa yang mengancam dan mengganggu kehidupan dan penghidupan masyarakat yang disebabkan, baik oleh faktor alam dan/atau faktor nonalam maupun faktor manusia sehingga mengakibatkan timbulnya korban jiwa manusia, kerusakan lingkungan, kerugian harta benda, dan dampak psikologis.

2. Bencana alam adalah bencana yang diakibatkan oleh peristiwa atau serangkaian peristiwa yang disebabkan oleh alam antara lain berupa gempa bumi, tsunami, gunung meletus, banjir, kekeringan, angin topan, dan tanah longsor.

3. Bencana non-alam adalah bencana yang diakibatkan oleh peristiwa atau rangkaian peristiwa nonalam yang antara lain berupa gagal teknologi, gagal modernisasi, epidemi, dan wabah penyakit.

4. Bencana sosial adalah bencana yang diakibatkan oleh peristiwa atau serangkaian peristiwa yang diakibatkan oleh manusia yang meliputi konflik sosial antarkelompok atau antarkomunitas masyarakat, dan teror [5].

Bencana alam dibagi menjadi tiga jenis berdasarkan penyebabnya, yakni :

1. Bencana alam geologis

Bencana alam geologis adalah bencana alam yang disebabkan oleh gaya-gaya dari dalam bumi. Contoh bencana alam geologis adalah gempa bumi, tsunami, letusan gunung berapi, longsor/gerakan tanah, amblesan atau abrasi.

2. Bencana alam klimatologis

Sedangkan bencana alam klimatologis adalah bencana alam yang disebabkan oleh perubahan iklim, suhu atau cuaca. Contoh bencana alam klimatologis adalah banjir, banjir bandang, angin puting beliung, kekeringan, hutan (bukan oleh manusia).

3. Bencana alam ekstra-terestrial

Bencana alam ekstra-terestrial, yaitu bencana alam yang disebabkan oleh gaya atau energi dari luar bumi, bencana alam geologis dan klimatologis lebih sering berdampak terhadap manusia. Contoh bencana alam ekstra-terestrial adalah impact atau hantaman atau benda dari angkasa luar.

Berdasarkan penyebabnya banjir dan kebakaran merupakan bencana alam klimatologis, karena disebabkan oleh perubahan iklim maupun cuaca. Banjir didefinisikan sebagai tergenangnya suatu tempat akibat meluapnya air yang melebihi kapasitas pembuangan air disuatu wilayah dan menimbulkan kerugian fisik, sosial dan ekonomi (Rahayu dkk, 2009). Banjir adalah ancaman musiman yang terjadi apabila meluapnya tubuh air dari saluran yang ada dan menggenangi wilayah sekitarnya. Banjir adalah ancaman alam yang paling sering terjadi dan paling banyak merugikan, baik dari segi kemanusiaan maupun ekonomi [6].

Definisi kebakaran menurut Asuransi secara umum adalah sesuatu yang benar-benar terbakar yang seharusnya tidak terbakar yang dibuktikan dengan adanya nyala api secara nyata, terjadi secara tidak sengaja, tiba-tiba serta menimbulkan kecelakaan atau kerugian.

\section{JasperServer}

JasperServer adalah kerangka kerja yang digunakan untuk membangun aplikasi Web yang mengintegrasikan JasperReports dan menggunakan JasperAnalysis sebagai implementasi dari Online Analytical Processing atau OLAP untuk melakukan tugas analitis. Penggunaan JasperReports, memungkinkan untuk membuat, jadwal dan menjalankan laporan, serta mengelola sumber daya [7].

\section{METODOLOGI}

Metode penelitian yang dilakukan untuk menganalisis penentuan daerah rawan bencana banjir dan kebakaran ini menggunakan 2 metode yaitu :

1. Metode melalui studi literatur.

2. Metode eksperimen dengan menggunakan beberapa tahapan diantaranya :
a. Pengumpulan data.
b. Cleaning Data.
c. Implementasi pada JasperServer.
d. Analisis hasil.

Adapun skema alur tahapan penelitian tersebut ditunjukpan pada Gambar 1.

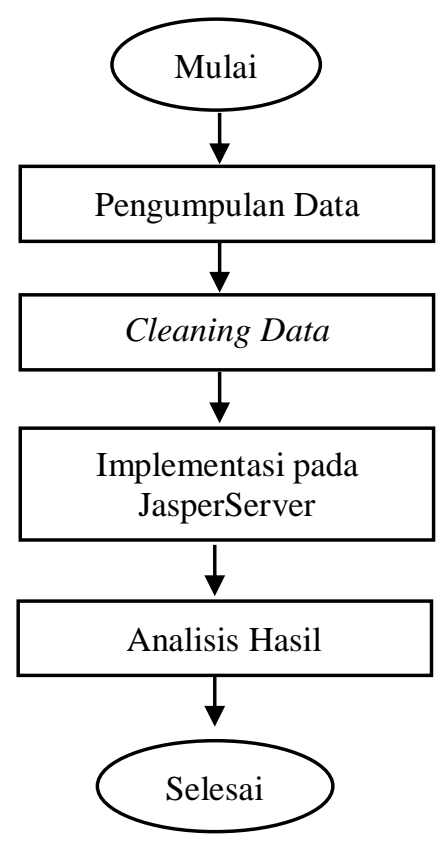

Gambar 1. Tahapan Penelitian

\section{PEMBAHASAN DAN HASIL}

Pada bab ini akan diuraikan mengenai hasil penelitian serta pembahasan dari hasil penelitian "Analisis Hasil Implementasi Business Intelligence Menentukan Daerah Rawan Banjir dan Kebakaran di Indonesia". Pembahasan ini berisi bagaimana hasil dari pengolahan data-data 
bencana banjir dan kebakaran yang ada sehingga nanti didapati output berupa grafik tentang daerah apa saja yang termasuk rawan bencana banjir dan kebakaran serta daerah yang aman dari bencana banjir dan kebakaran dari seluruh provinsi di Indonesia.

\section{A. Pengumpulan Data}

Data yang didapatkan berasal dari Badan Nasional Penanggulangan Bencana. Data tersebut merupakan data sampel tentang data bencana banjir dan kebakaran yang diambil secara acak di seluruh Indonesia. Data bencana banjir yang diperoleh sebanyak 1209 kejadian, serta data kebakaran sebanyak 979 kejadian. Data yang diperoleh dalam bentuk format Excel, kemudian disesuaikan agar dapat di import ke database dan dianalisa menggunakan JasperServer.

\section{B. Cleaning Data}

Cleaning Data adalah suatu proses mendeteksi dan memperbaiki (atau menghapus) data set, tabel, dan database yang korup atau tidak akurat. Istilah ini mengacu pada identifikasi data yang tidak lengkap, tidak benar, tidak tepat, dan tidak relevan, kemudian dirty data tersebut akan diganti, dimodifikasi atau dihapus. Proses cleaning data ini cukup penting dalam pembangunan data warehouse untuk mencegah terjadinya duplikat data, ambigu pada data dan konflik penamaan [8].

\section{Implementasi pada JasperServer}

Setelah proses import data berhasil dilakukakan, kemudian lakukan pengolahan data pada JasperServer. Langkah-langkah yang dilakukan untuk mengolah data pada JasperServer, yakni:

1. Membuat sebuah folder baru pada repository.

2. Kemudian membuat sebuah data source, data source ini berguna untuk menghubungkan JasperServer dengan sumber data. Pada penelitian kali ini menggunakan JDBC PostgreeSQL. Setelah itu menyimpan data source ini kedalam folder yang sudah dibuat sebelumnya.

3. Langkah selanjutnya yaitu membuat Domain. Domain tersebut berguna untuk mendefinisikan struktur dari data source yang akan digunakan pada Ad-Hoc. Pada domain ini akan mengambil tabel yang diperlukan dan menentukan relasi antar tabel tersebut, serta membuat fungsi agregat. Misalkan membuat fungsi agregat baru dengan nama profit yang mempunyai tipe data bigdecimal, dengan rumus profit $=$ sales - store .

4. Selanjutnya membuat Ad-Hoc, kegunaan Ad-Hoc adalah memvisualisasikan data untuk di analisis dan membuat report. Pada Ad-Hoc juga bisa difenisikan field baru.

5. Tahapan terakhir adalah membuat sebuah dashboard. Dashboard merupakan kumpulan dari beberapa $A d$ Hoc. Dalam pembahasan kali ini ditampilkan dashboard banjir dan dashboard kebakaran.
a. Dashboard Banjir

Pada dashboard banjir akan ditampilkan $A d$ Hoc jumlah kejadian banjir tahun 2011-2016, Ad$H o c$ kerugian banjir dan Ad-Hoc korban banjir yang sudah difilter dari setiap masing-masing provinsi, sehingga jika salah satu provinsi diklik maka semua $A d-H o c$ yang berhubungan dengan provinsi tersebut akan menampilkan data kejadian berupa banyak banjir, kerugian banjir dan korban banjir. Dashboard banjir dari seluruh provinsi di Indonesia dapat dilihat seperti Gambar 2.

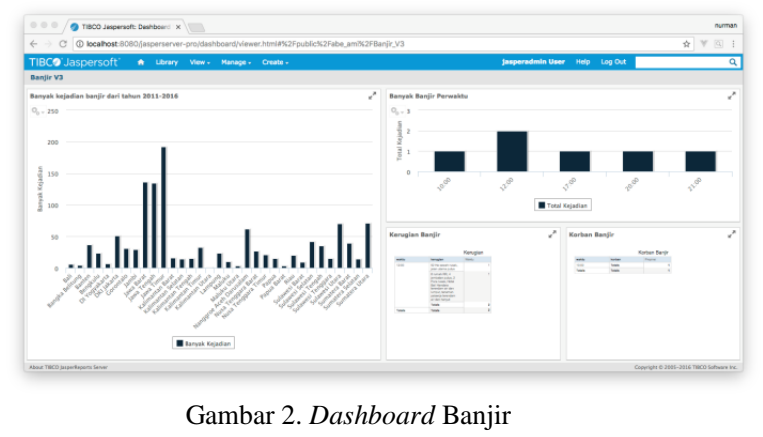

Pada dashboard banjir dapat dilihat grafik jumlah banyaknya banjir dari tahun 2011-2016 di seluruh provinsi yang ada di Indonesia seperti Gambar 3.

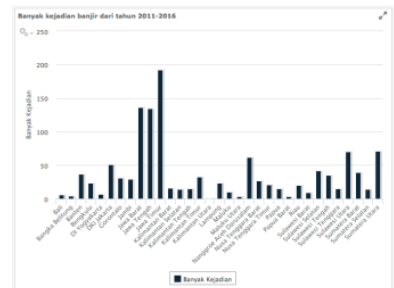

Gambar 3. Ad-Hoc Jumlah Banjir Tahun 2011-2016 Seluruh Provinsi di Indonesia

Kemudian dapat memperbesar grafik untuk melihat provinsi mana saja yang sering rawan banjir seperti Gambar 4.

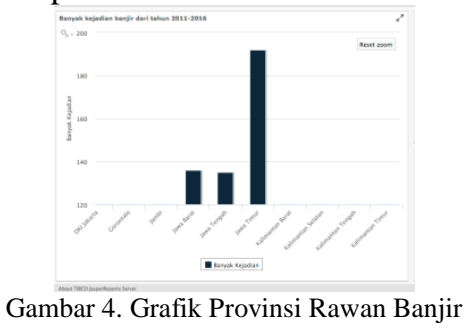

Pada Gambar 4 tersebut telah menampilkan tiga provinsi teratas yang sering dilanda banjir. Jika diklik provinsi daerah paling rawan banjir yaitu Jawa Timur, maka akan tampil informasi berupa Ad-Hoc grafik waktu kejadian banjir, kerugian banjir tersebut, dan jumlah korban banjir di Jawa Timur seperti Gambar 5. 


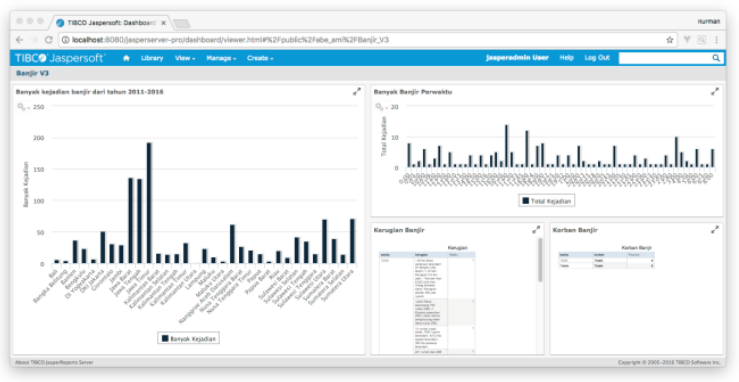

Gambar 5. Dashboard Banjir Provinsi Jawa Timur

Kemudian apabila ingin melihat grafik waktu bencana banjir, dapat dklik grafik tersebut dan dapat diperbesar seperti Gambar 6.

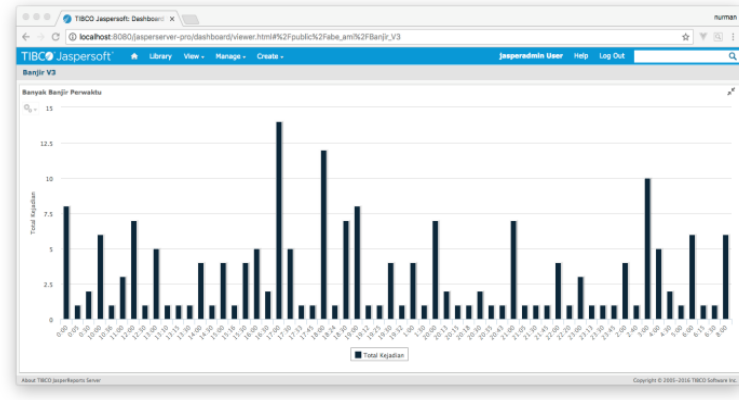

Gambar 6. Dashboard Waktu Kejadian Banjir Provinsi Jawa Timur

Informasi lain yang dapat dilihat yakni kerugian banjir dan banyak korban bencana banjir tersebut seperti Gambar 7 dan Gambar 8.

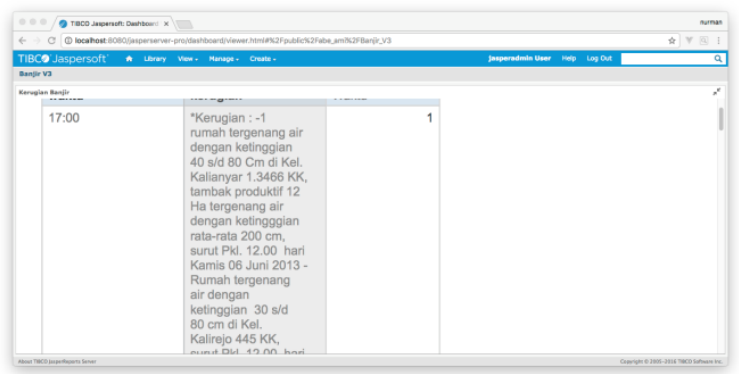

Gambar 7. Dashboard Kerugian Banjir Provinsi Jawa Timur

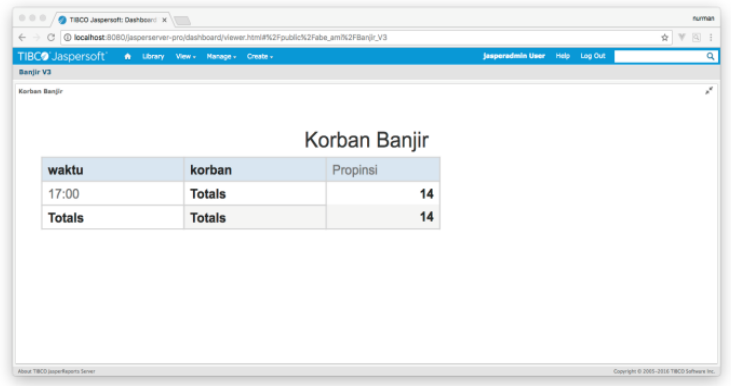

Gambar 8. Dashboard Korban Banjir Provinsi Jawa Timur

b. Dashboard Kebakaran

Pada dashboard kebakaran akan ditampilkan Ad-Hoc jumlah kejadian kebakaran tahun 2011-2016, Ad-Hoc waktu kejadian kebakaran, Ad-Hoc lokasi kebakaran, dan Ad-Hoc korban kebakaran yang sudah difilter dari setiap masing-masing provinsi, sehingga jika salah satu provinsi diklik maka semua Ad-Hoc yang berhubungan dengan provinsi tersebut akan menampilkan jumlah kejadian kebakaran, waktu kejadian kebakaran, lokasi kebakaran, dan korban kebakaran. Dashboard kebakaran dari seluruh provinsi di Indonesia dapat dilihat seperti Gambar 9.

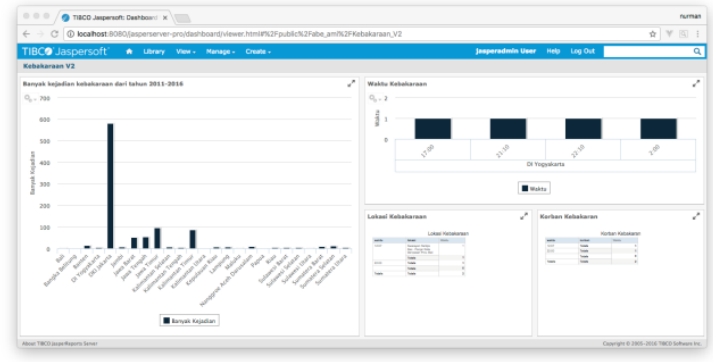

Gambar 9. Dashboard Kebakaran

Kemudian dari Gambar 9 tersebut dapat dilihat bahwa Provinsi DKI Jakarta merupakan provinsi yang paling rawan terjadi bencana kebakaran. Apabila diklik Provinsi DKI Jakarta maka akan tampil waktu kejadian kebakaran, lokasi kebakaran, dan korban kebakaran seperti Gambar 10, Gambar 11, dan Gambar 12.

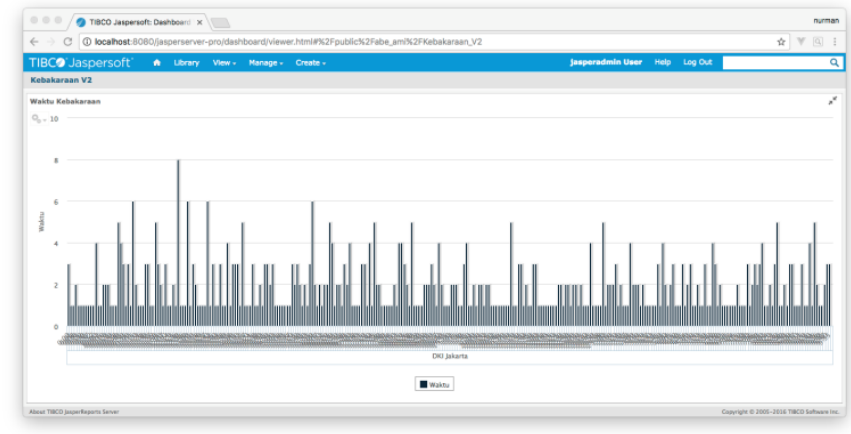

Gambar 10. Dashboard Waktu Kejadian Kebakaran Provinsi DKI Jakarta

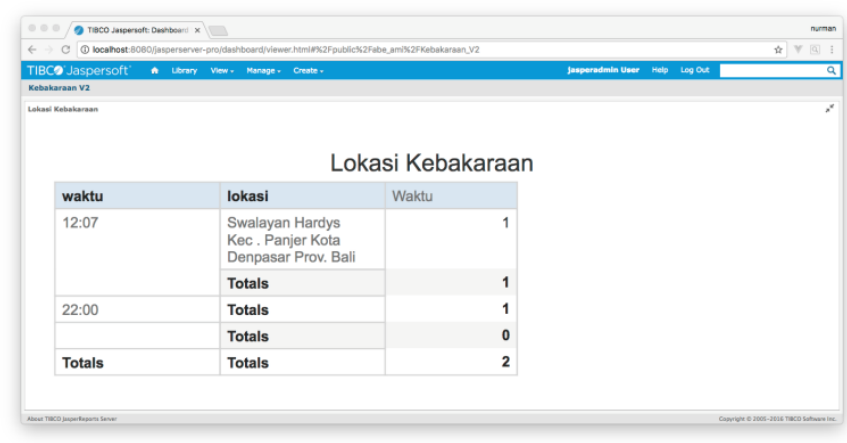

Gambar 11. Dashboard Lokasi Kebakaran Provinsi DKI Jakarta 


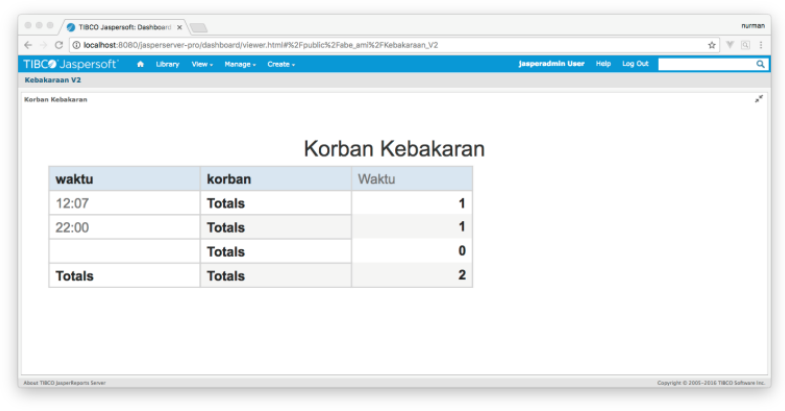

Gambar 12. Dashboard Korban Kebakaran Provinsi DKI Jakarta

\section{Analisis Hasil}

Pada penelitian tersebut yang menggunakan JasperServer sebagai aplikasi Business Intelligence dalam memperoleh informasi baik berupa grafik maupun datadata yang diperlukan dapat di analisis bahwa daerah yang rawan banjir di Indonesia adalah Provinsi Jawa Timur. Provinsi Jawa Timur menempati posisi pertama, kemudian baru Provinsi Jawa Barat dan disusul oleh Provinsi Jawa Tengah. Pada bagian sebelumnya telah dipaparkan grafik kejadian banjir di Indonesia, serta diperoleh informasi bahwa bencana banjir di Provinsi Jawa Timur banyak terjadi pada pukul 17.00 WIB.

Sedangkan bencana kebakaran banyak terjadi di daerah DKI Jakarta. Sesuai data tersebut maka tiga provinsi teratas yang rawan terjadi bencana kebakaran adalah DKI Jakarta, Jawa Timur, dan Kalimantan Timur. Kemudian dari grafik yang telah dibahas pada bagian sebelumnya dapat diperoleh informasi bahwa bencana kebakaran pada provinsi DKI Jakarta banyak terjadi pada pukul 12.30 WIB.

\section{KESIMPULAN}

Banjir dan kebakaran merupakan bencana yang sering terjadi di Indonesia sepanjang tahun. Hal tersebut bisa terjadi karena musim di Indonesia yang hanya dua, yaitu musim kemarau dan musim hujan. Pada musim hujan yang terjadi adalah sungai dan bandar tidak mampu menampung aliran air, sehingga air meluap pada aliran tersebut dan merendam daratan. Sedangkan, pada musim kemarau yang terjadi adalah banyaknya peristiwa kebakaran baik kebakaran hutan maupun kebakaran rumah penduduk. Kebakaran rumah penduduk terjadi karena adanya konsleting listrik maupun adanya pemicu api, apalagi jika hal tersebut terjadi pada musim jemarau maka api dapat dengan cepat dan buasnya melalap seisi rumah penduduk.

Maka dari itu, berdasarkan data banjir dan kebakaran yang terjadi Indonesia menggunakan bantuan aplikasi JasperServer, maka hasil yang dapat disimpulkan yaitu:

1. Jawa Timur merupakan provinsi dengan kejadian banjir tebanyak sepanjang tahun 2011 - 2016, yakni dengan kurang lebih dua ratus kejadian.

2. Banjir di Jawa Timur sepanjang tahun 2011 - 2016, kabanyakan terjadi pada pukul 17.00 WIB.
3. DKI Jakarta merupakan provinsi dengan kejadian kebakaran terbanyak sepanjang tahun 2011 - 2016, dengan total kejadian kurang lebih enam ratus kejadian.

4. Kebakaran di DKI Jakarta sepanjang tahun 2011 2016. Kebanyakan terjadi pada pukul 12.30 WIB.

JasperServer sangat membantu untuk memperoleh informasi provinsi yang termasuk rawan banjir dan kebakaran serta provinsi yang aman dari banjir dan kebakaran.

\section{REFERENSI}

[1] E. Turban, Decision Support and Business Intelligence Systems, Upper Saddle River: Pearson Education, 2007.

[2] E. Miranda, Pengembangan Business Intelligence Bagi Perkembangan Bisnis Perusahaan, vol. vol. 2, pp. pp. 111-116, 2008.

[3] Imelda, "Business Intelligence," Majalah Ilmiah UNIKOM, vol. 11

[4] S. W. S. S. W. Suparto Darudiato, "Business Intelligence : Konsep dan Metode".

[5] B. N. P. Bencana, "Definisi dan Jenis bencana," BNPB, 2012. [Online]. Available: Jhttp://www. bnpd. go. id/. [Diakses 2004 2017].

[6] IDEP, Panduan Umum Penanggulangan Bencana Berbasis Masyarakat, Bali: Yayasan IDEP, 2007.

[7] K. C. J. P. Laudon, dalam Essen-tials of Business Information Systems 7th Edition, Pearson Prentice Hall, 2008.

[8] A. Riezka, Analisis dan Implementasi Data-Cleaning dengan Menggunakan Metode Multi-Pass Neighborhood (MPN), 2011. 